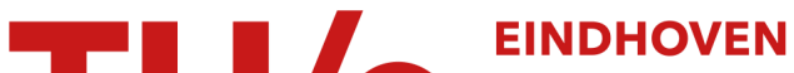 UNIVERSITY OF TECHNOLOGY
}

\section{Computational performance analysis of overheating mitigation measures in parked vehicles}

\section{Citation for published version (APA):}

Soulios, V., Loonen, R. C. G. M., Metavitsiadis, V., \& Hensen, J. L. M. (2018). Computational performance analysis of overheating mitigation measures in parked vehicles. Applied Energy, 231, 635-644.

https://doi.org/10.1016/j.apenergy.2018.09.149

DOI:

10.1016/j.apenergy.2018.09.149

Document status and date:

Published: 01/12/2018

\section{Document Version:}

Accepted manuscript including changes made at the peer-review stage

\section{Please check the document version of this publication:}

- A submitted manuscript is the version of the article upon submission and before peer-review. There can be important differences between the submitted version and the official published version of record. People interested in the research are advised to contact the author for the final version of the publication, or visit the $\mathrm{DOI}$ to the publisher's website.

- The final author version and the galley proof are versions of the publication after peer review.

- The final published version features the final layout of the paper including the volume, issue and page numbers.

Link to publication

\section{General rights}

Copyright and moral rights for the publications made accessible in the public portal are retained by the authors and/or other copyright owners and it is a condition of accessing publications that users recognise and abide by the legal requirements associated with these rights.

- Users may download and print one copy of any publication from the public portal for the purpose of private study or research.

- You may not further distribute the material or use it for any profit-making activity or commercial gain

- You may freely distribute the URL identifying the publication in the public portal.

If the publication is distributed under the terms of Article 25fa of the Dutch Copyright Act, indicated by the "Taverne" license above, please follow below link for the End User Agreement:

www.tue.nl/taverne

Take down policy

If you believe that this document breaches copyright please contact us at:

openaccess@tue.nl

providing details and we will investigate your claim. 


\title{
Computational performance analysis of overheating mitigation measures in parked vehicles
}

\author{
V. Soulios ${ }^{a}$, R.C.G.M. Loonen ${ }^{b}$, V. Metavitsiadis ${ }^{a}$, J.L.M. Hensen ${ }^{b}$ \\ ${ }^{a}$ KU Leuven, Building Physics Section, Kasteelpark Arenberg 40, B-3001 Leuven, Belgium \\ ${ }^{b}$ Unit Building Physics and Services, Eindhoven University of Technology, the Netherlands
}

\begin{abstract}
Parked vehicles have the tendency to overheat quickly. This can lead to a negative impact on the thermal comfort of the driver and its passengers, as well as intensive use of air conditioning systems, and thus fuel consumption of the vehicle or, in the case of electric mobility, a reduced cruising range. In the search for effective measures to mitigate this effect, important guidance can be provided by the field of sustainable building design. On the one hand, inspiration can come from design strategies in terms of shapes and advanced cover materials, but this paper advocates that this can also pertain to the simulation-based design support tools that are used by building engineers. This paper first presents the results of a thermal soak test, and then uses this data to demonstrate the suitability of the building performance simulation tool EnergyPlus for predicting the thermal behavior of parked vehicles. This fit-for-purpose validated model is used to evaluate the performance of three overheating mitigation measures for two car models in two climates. The results show that spectrally selective glazing can reduce the cabin air temperature by $12.5^{\circ} \mathrm{C}$ and when combined with solar reflective opaque surfaces, the reduction of cabin air temperature can reach $23.8^{\circ} \mathrm{C}$. Increased use of building performance simulation in the automotive domain can help to further optimize the overheating reduction potential of cars.
\end{abstract}

Keywords: Overheating, thermal soak test, vehicle modeling, building performance simulation

\section{Introduction}

Management of thermal conditions inside vehicles is important to ensure the comfort of passengers (Devonshire \& Sayer, 2005) (Lin, Tzu-Ping et al., 2010). It is of particular concern, due to the existing correlation between high cabin temperatures and reduced driver vigilance, and hence, higher accident rates (Wyon, David, \& Norin, 1996) (Lenzuni et al., 2014). Already after a short period of time, the cabins of vehicles parked in unshaded areas can reach temperatures that are 20 to $30^{\circ} \mathrm{C}$ higher than the ambient (Grundstein, Meentemeyer, \& Dowd, 2009) (Dadour et al., 2011). Automobile air conditioning (AAC) systems used to be an exclusive add-on option. However, nowadays, nearly all new cars are sold with AAC systems, in both industrialized and developing countries (Minjares, 2011) (Daly, 2011). AAC use is identified as the largest contributor to the auxiliary energy consumption of cars (i.e. the part that is not 
used for propelling the vehicle), and hence has a great influence on fuel economy and associated emissions (Weilenmann, Vasic, Stettler, \& Novak, 2005). As a consequence, there has been significant attention for enhancing the efficiency of AAC systems, as well as for improving their operation strategies (Khayyam, Kouzani, Hu \& Nahavandi, 2011) (Nielsen, Uddheim, \& Dalenback, 2016).

With the rise of electric vehicles (EVs), car manufacturers for the first time also have an intrinsic motivation to promote reduced AAC use, because it has a direct influence on driving range; one of the most important factors in the purchasing decision of EVs (Carley, Krause, Lane, \& Graham, 2016) (Zhang et al., 2017) (Liu, 2017). Studies have shown that the seasonally-averaged loss in EV battery range due to AAC energy use can go above $23 \%$ (Kambly \& Thomas, 2015)(Fiori, Ahn, \& Rakha, 2016). Finding ways to reduce this impact can act as a main incentive towards widespread adoption of sustainable electric mobility. Preventing that cars already get too warm when they are not in use, is a good strategy to begin with.

The design of the body of a vehicle (i.e. shape, size and materials selection) has a considerable influence on its potential for overheating (Levinson et al., 2011). In this context, it is interesting to draw a parallel to the building industry. While passive overheating reduction measures are commonly applied and quite well understood for building envelopes (Sadineni, Madala, \& Boehm, 2011)(Loonen, Trčka, Cóstola, Hensen, 2013)(Amaral et al., 2016), it is a relatively new field of investigation in the automotive sector. The physical principles that govern the thermal energy balance of the exterior shell are the same for parked vehicles as for buildings. Not only can car manufacturers and designers take inspiration from proven technologies in the construction sector (Pan et al., 2017), but they can potentially also take advantage of the performance analysis and design support approaches that have been developed in this field. The potential of using computational building performance simulation tools has previously been explored for long-haul truck cabins (Lustbader, Rugh, Rister, \& Venson, 2011), but applications for passenger vehicles were not found in literature.

This paper has two main objectives. The first one is to validate the suitability of a building energy simulation program for the purpose of predicting the heat transfer and temperature profiles in parked vehicles. This is done using an experimental thermal soak test and the simulation program EnergyPlus, as described in Section 2. The second objective is to use the simulation tool for a comparative performance analysis of three overheating reduction measures for different climatic conditions and vehicle types. Three overheating reduction measures are investigated: spectrally selective glazing, solar reflective opaque surfaces, and windshield sunshades. The set-up of this case study is described in Section 3, and the results for four characteristic days, as well as the annual performance, is discussed in Section 4. The last Section of this article (Section 5) concludes by summarizing the main findings and providing directions for further research.

\section{Experimental validation of the simulation model}

Most of the widely-used building performance simulation (BPS) software tools have undergone rigorous validation and quality assurance procedures (Clarke \& Hensen, 2015). The governing physical principles for heat and mass transfer in cars and buildings are similar. However, it is also known that there are certain "hidden" assumptions and semi-empirical formulations in BPS models that work well for buildings, but may impair the credibility of predictions when used outside the intended application domain (Crawley, 
Hand, Kummert \& Griffith, 2008). Before BPS can confidently be applied to model the thermal performance of vehicle cabins, it is essential to ascertain the quality of the predictions. There are a few papers available in literature that present results of temperature measurements in parked cars (Chakroun \& Al-Fahed, 1997) (Abd-Fadeel \& Hassanein, 2013) (Grundstein, Meentemeyer, \& Dowd, 2009) (Dadour $\&$ al, 2011). However, these papers do not provide all information that would be needed to set up a comprehensive validation study, such as exact weather conditions of the day of the experiment and the material properties of vehicle body and windows.

In this study, a new experimental campaign was carried out, to overcome the data availability limitations in published literature.

\subsection{Experimental procedures}

A dark blue Citroën C3 (Fig.1), is used for the thermal soak tests. The shape and dimensions of the body, including side, rear, and front windows are shown in Fig. 2.

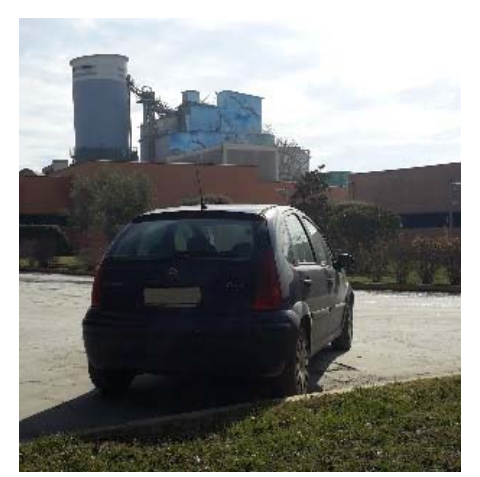

Fig. 1: Vehicle used in experiments: Dark blue Citroën C3, Latitude: 40:7, Longitude: 22:95, Elevation: $112 \mathrm{~m}$, time-zone: UTC/GMT +2
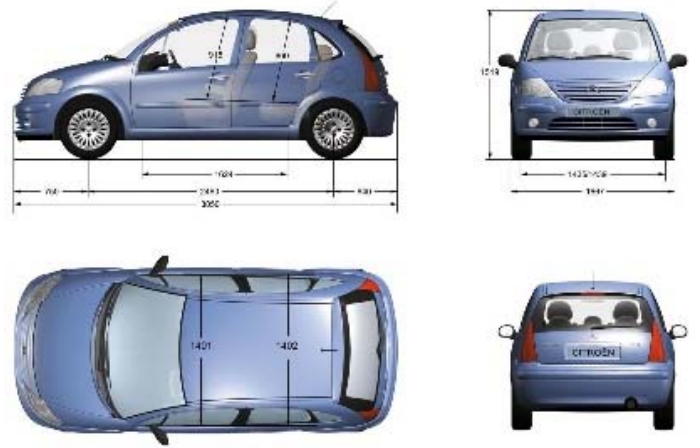

Fig. 2: Dimensions of the vehicle used in experiments (Citroen C3)

The soak test was performed by parking the car with its front facing the south-east direction. The experiment was performed under clear sky conditions ( $30^{\text {th }}$ March 2016), exposed to direct sunlight in a shading-free area, near the meteorological station of TITAN cement company S.A. at the site in Thessaloniki, Greece. The meteorological station is located at an elevation of 112 meters, $40.7^{\circ}$ latitude and $22.95^{\circ}$ longitude. Three air temperature sensors were placed inside the vehicle's cabin in order to investigate the interior temperature distribution. The first sensor was placed close to the dashboard, while the second sensor was placed behind the driver's seat. Finally, a third sensor was placed between the front seats, at the passenger's breathing level. The locations where the three sensors were placed are depicted in Fig. 3. All sensors were not in contact with any surface and were surrounded by an aluminum foil cylinder that functioned as a radiation shield, so that the sensors would not be affected by direct solar radiation.

The vehicle's doors and windows remained sealed during the experiment and the measurements were obtained through the thermometers' recorder, which was placed outside of the vehicle and was connected to the sensors through a cable. 
Dry-bulb outside air temperature and global horizontal solar irradiance during the time of the experiment were taken from the neighboring weather station.

\subsection{Experimental outcomes}

Ambient air temperature ranged from $14.3^{\circ} \mathrm{C}$ to $21.4^{\circ} \mathrm{C}$ at the day of the experiment. Fig. 4 clearly illustrates that there is a large temperature gradient inside the vehicle cabin, as shown particularly by the values of sensors 1 and 3 . This temperature variation would also be experienced by the passengers. Fig. 4 also indicates a strong correlation of cabin air temperature with solar radiation and ambient air temperature. Sensor 2, which is placed behind the driver's seat, is less affected by solar radiation than sensors 1 and 3 . The thermal mass of the vehicle causes the cabin air temperature to remain at high levels after solar radiation and ambient temperature start to decline.

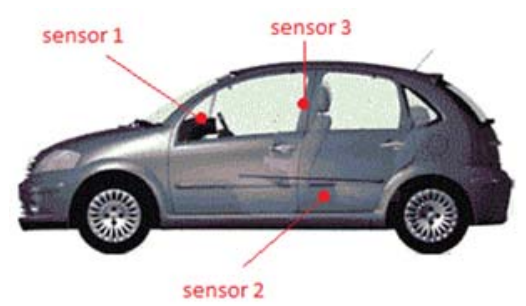

Fig. 3: Locations of the cabin temperature sensors.

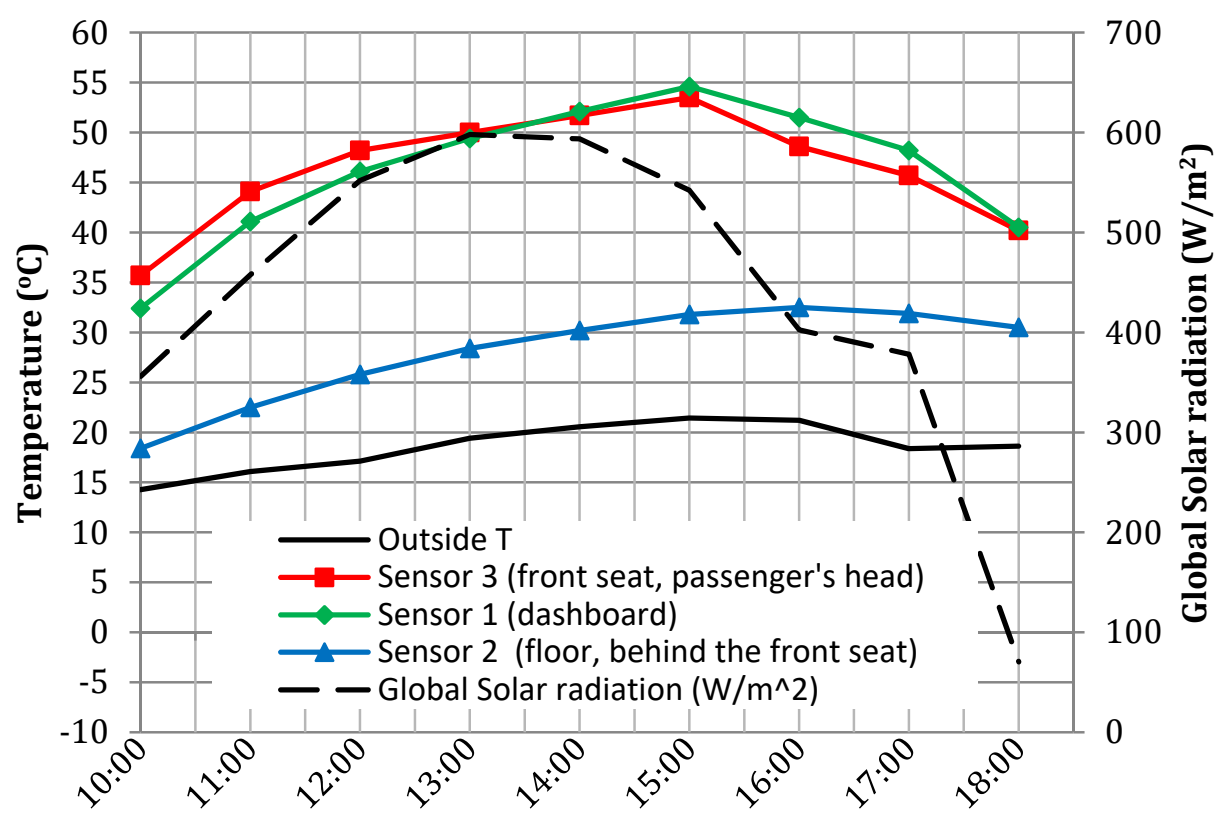

Time (h)

Fig.4: Experimental data for cabin temperature of Citroën C3, sensor 1 placed in dashboard, sensor 2 behind the driver seat and sensor 3 face height in the front seat

\subsection{Inputs of the simulation}

A computational model of the same car was created, in order to assess the usability of the building performance simulation tool EnergyPlus for predicting the thermal behavior of parked vehicles. EnergyPlus is a whole building energy simulation program, that is mostly used by architects and building 
engineers to predict energy consumption for heating, cooling and ventilation, as well as for modeling the indoor environmental quality of buildings. EnergyPlus makes use of finite difference models to calculate dynamic heat transfer and storage effects, and operates on the basis of heat balance principles concerning convective and radiant effects to calculate node and surface temperatures for every time step of the simulation (U.S. Department of Energy, 2016). EnergyPlus is among the most widely-used building performance simulation programs, and its underlying code has gone through many validation and verification procedures. This study compares EnergyPlus predictions to measurements, to gain confidence in the modeling results with respect to aspects that are critical for understanding thermal comfort in parked vehicles, such as scalability issues regarding heat transfer in small confined spaces and transient warm-up phenomena.

As a first step, the geometry of the vehicle was abstracted and then implemented using SketchUp (Fig. 5). This geometrical model was then exported to EnergyPlus.

Weather data for a specific site are required for accurate building performance simulations in a validation exercise. For that purpose, the locally-recorded weather data were converted to weather files that could be used by EnergyPlus. Throughout the simulations, a time-step of 10 minutes was used, to coincide with the sampling rate of the thermometers inside the cabin.

Three different thermal zones were modeled: engine zone (front), cabin zone (middle) and trunk zone (rear). The analysis of the simulation results focuses solely on the cabin zone. All the surfaces that are exposed to the outside are assigned with "outdoors" boundary conditions, along with sun and wind exposure. This is also the case with the surface below the engine zone, as it is exposed to outdoor climatic conditions. The distance between the bottom surface of the vehicle models and the ground is the same as with an actual vehicle, although wheels are not part of the models used in the simulations. A full exterior solar distribution was selected to account for insolation in a detailed way (U.S. Department of Energy, 2016).

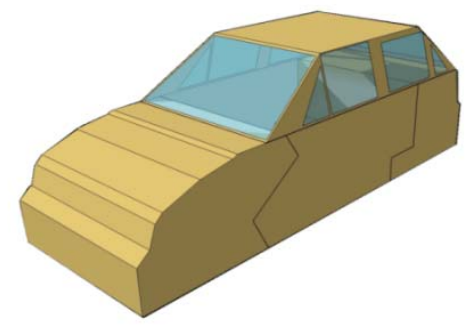

Fig. 5: SketchUp model of Citroën C3.

In simulation programs such as EnergyPlus, it is not possible for simulation users to explicitly set the initial temperature values at the start of the simulation. A pre-simulation warm-up period is normally used to overcome this issue. The length of this initialization period should be chosen in accordance with the thermal time constant of the system that is being investigated. In the present study, it was found that a minimum warm-up period of 6 days leads to convergence of the solution, and hence, satisfactory results.

Three different materials were chosen for the car's body: one material for the opaque surfaces, one for the windshield construction and one for the rear, left and right windows (Table 1). All transparent surfaces were modeled in a detailed way, using EnergyPlus' built-in fenestration model that accounts for both 
spectral and angle-dependent optical characteristics. Opaque parts of the shell were modeled as homogeneous and isotropic materials, following the best-practice guidelines of the VSOLE model developed at the National Renewable Energy Laboratory (NREL) (Rugh, 2002). The resolution of the model could be increased by inserting layer-by-layer material properties, but such an approach would be impeded by the limited availability of reliable input data and the fact that the low thermal mass and low thermal resistance of the opaque parts would lead to marginal differences.

Table 1: Vehicle body and window material properties. Source: (Fayazbakhsh \& Bahrami, 2013), (VSOLE).

\begin{tabular}{|c|c|c|c|}
\hline \multicolumn{4}{|c|}{ Vehicle Body Properties } \\
\hline & Thickness (m) & 0.01 & \\
\hline & Conductivity (W/mK) & 0.2 & \\
\hline & Density $\left(\mathrm{kg} / \mathrm{m}^{\wedge} 3\right)$ & 1500 & \\
\hline & Specific heat $\left(\mathrm{J} / \mathrm{kg}^{*} \mathrm{~K}\right)$ & 1000 & \\
\hline & Thermal Absorptance & 0.83 & \\
\hline & Solar Absorptance & 0.95 & \\
\hline & Visible Absorptance & 0.9 & \\
\hline \multicolumn{2}{|l|}{ Window Properties } & Windshield & $\begin{array}{c}\text { Rear-Left- } \\
\text { Right Window }\end{array}$ \\
\hline \multicolumn{2}{|c|}{ Thickness (m) } & 0.003 & 0.003 \\
\hline \multicolumn{2}{|c|}{ Solar Transmittance At Normal Incidence } & 0.74 & 0.812 \\
\hline \multicolumn{2}{|c|}{ Front Side Solar Reflectance At Normal Incidence } & 0.07 & 0.075 \\
\hline \multicolumn{2}{|c|}{ Back Side Solar Reflectance At Normal Incidence } & 0.07 & 0.075 \\
\hline \multicolumn{2}{|c|}{ Visible Transmittance At Normal Incidence } & 0.868 & 0.885 \\
\hline \multicolumn{2}{|c|}{ Front Side Visible Reflectance At Normal Incidence } & 0.08 & 0.085 \\
\hline \multicolumn{2}{|c|}{ Back Side Visible Reflectance At Normal Incidence } & 0.08 & 0.085 \\
\hline \multicolumn{2}{|c|}{ Infrared Transmittance At Normal Incidence } & 0.688 & 0.764 \\
\hline \multicolumn{2}{|c|}{ Front Side Infrared Hemispherical Emissivity } & 0.248 & 0.168 \\
\hline \multicolumn{2}{|c|}{ Back Side Infrared Hemispherical Emissivity } & 0.248 & 0.168 \\
\hline \multicolumn{2}{|c|}{ Conductivity $(\mathrm{W} / \mathrm{mK})$} & 1.05 & 1.05 \\
\hline \multicolumn{2}{|c|}{ Dirt Correction Factor For Solar And Visible } & 1 & 1 \\
\hline
\end{tabular}

In order for the interior objects to be adequately represented in the simulation, an internal mass parameter was defined. The internal mass multiplier is a semi-empirical simulation parameter that accounts for the extra thermal inertia due to non-structural materials, and is hard to be specified since there is little information available about the values that should correspond to it. For that reason, different approaches of internal mass multiplier values for $4 \mathrm{~m}^{2}$ surface area of car seats were tested. Polyisocyanurate was selected as the material of car seats, with properties presented in Table 2. The quantitative indicators, root mean squared error (RMSE) and mean absolute error (MAE) between measured and predicted cabin temperatures were compared for internal mass multipliers ranging from 1 to 10. Eventually, multiplier values of 2 and 3 were selected as the best option, and therefore, an internal mass multiplier of 2.5 was selected for use in further analyses.

Table 2: Properties of Polyisocyanurate. Source: OpenStudio library

\begin{tabular}{lc}
\multicolumn{2}{c}{ Properties of Polyisocyanurate } \\
\hline Thickness $(\mathrm{m})$ & 0.1016 \\
Conductivity $(\mathrm{W} / \mathrm{mK})$ & 0.02 \\
Density $\left(\mathrm{kg} / \mathrm{m}^{3}\right)$ & 32 \\
Specific Heat $\left(\mathrm{J} / \mathrm{kg}^{*} \mathrm{~K}\right)$ & 920
\end{tabular}




\subsection{Comparison between measurements and simulation}

Fig. 6 compares the experimental and simulation results for the thermal soak test, regarding the variation of cabin air temperature with respect to time. The results show that there is a high level of agreement between the measured and predicted warm-up and cool-down rates $\left({ }^{\circ} \mathrm{C} / \mathrm{h}\right)$ for representative points in the cabin. Moreover, it appears that the model is able to predict the peak air temperature reasonably well.

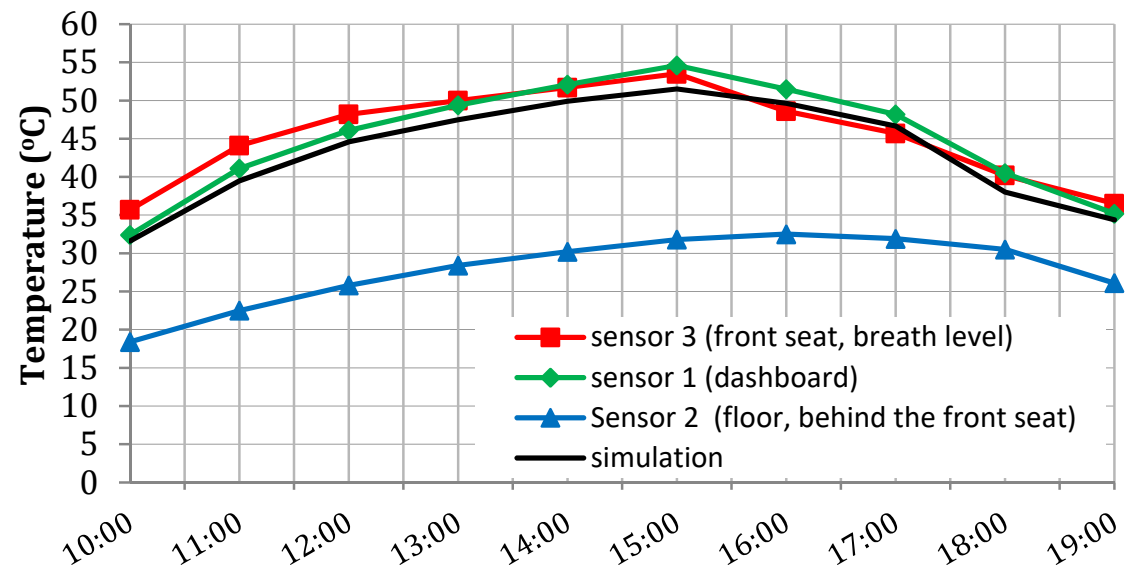

Time (h)

Fig.6: Comparison of experimental and simulation results.

It is difficult, however, to make direct comparisons between local temperature measurements and the output reported by EnergyPlus. EnergyPlus assumes a well-mixed air volume, and therefore a uniform temperature inside the thermal zone (U.S. Department of Energy, 2016). In reality, local absorption of sunlight and natural convection will induce significant air temperature differences as a function of position inside the cabin. For example, studies by (Rugh, 2002) (Fiser, Pokorny, Podola, \& Jicha, 2013) have used a grid of sensor points to demonstrate that temperature can vary by several ${ }^{\circ} \mathrm{C}$ in a range of just a few centimeters. Simulation studies with computational fluid dynamics (CFD) have furthermore demonstrated that the temperature difference of approximately $20^{\circ} \mathrm{C}$, that is measured between sensor points in the front (sensors 1 and 3 ) and near the floor behind the front seat (sensor2), are representative (Konstantinov \& Wagner, 2016).

The results presented in Fig. 6 give sufficient confidence that EnergyPlus, although it is a building performance simulation tool, is also capable of producing accurate estimations for heat transfer and temperature evolution in parked vehicles. It would have been a possibility to use a higher resolution airflow modeling approach (e.g. CFD) to obtain spatial temperature distributions inside the cabin. However, considering the purpose of the present simulation study (i.e. a comparative analysis with a focus on the energy balance), the potential added value of such an approach was deemed insufficient. Similarly, it was decided to refrain from the use of the Three-Node Displacement Ventilation RoomAir Model in 
EnergyPlus, because of its reliance on empirically-derived flow coefficients, which have only been determined for thermal stratification in buildings with displacement ventilation or cooling systems with underfloor air distribution. Moreover, it should be noted that due to the large number of extra parameters and assumptions that are needed (e.g. boundary conditions and properties of turbulence models or opening types) and the associated level of uncertainty this introduces, using a model of higher resolution does not necessarily lead to more accurate results.

\section{Case study: Overheating Mitigation Measures}

\subsection{Introduction}

Three overheating mitigation measures are considered in this study: i) spectrally selective glazing for the vehicle windows, ii) solar reflective opaque surfaces and iii) the placing of shadings on the windshield of the vehicle.

Two different vehicle types were selected for the simulations: Citroën C3, which is the car that was used for the validation procedure and can be considered as a typical B-segment car, and Tesla model S (all-glass panoramic roof version), which is an electric luxury sedan that was selected due to the relatively large area of the cabin's surface that is covered by windows. Although Tesla $\mathrm{S}$ already uses spectrally selective glazing for the panoramic roof construction, in the baseline scenario the use of conventional glass was selected. The geometry of Tesla model S, as it was designed in SketchUp, is shown in Fig. 7.

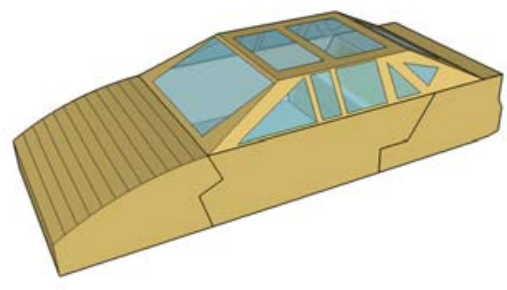

Fig. 7: SketchUp model of Tesla S.

This study considers the climates of Thessaloniki, Greece, and Amsterdam, the Netherlands. To generate results that cover a large spectrum of different climatic conditions, four different daily situations were selected, according to temperature and radiation values, as shown in Table 3 . This data is taken from the typical meteorological year (TMY) files for both locations. In each of these occasions, no significant shortterm fluctuations in solar radiation during the day were observed. Also, the cumulative solar irradiance for each of the selected days was slightly higher compared to the days just before and after. In that way, it is likely that the selected days represent typical clear-sky days for each occasion. The cars are parked in an unobstructed area, with their front facing south. An analysis of the simulation results for these four representative days is presented in Section 4.1, followed by an annual performance evaluation in Section 4.2. More details about the three overheating reduction measures is first given in Section 3.2.

Table 3: The four representative climatic conditions.

\begin{tabular}{|c|c|c|c|c|}
\hline & Temperature & Radiation & Location & Day \\
\hline A & $\left(\max .7 .2^{\circ} \mathrm{C}\right)$ & Low (max. $500 \mathrm{Wh} / \mathrm{m}^{2}$ ) & Amsterdam, The Netherlands & March $6^{\text {th }}$ \\
\hline B & Medium (max. $\left.18^{\circ} \mathrm{C}\right)$ & Medium-L (max. $\left.726 \mathrm{Wh} / \mathrm{m}^{2}\right)$ & Thessaloniki, Greece & March $15^{\text {th }}$ \\
\hline C & Medium(max. $\left.18.9^{\circ} \mathrm{C}\right)$ & Medium-H(max. $\left.831 \mathrm{Wh} / \mathrm{m}^{2}\right)$ & Amsterdam, The Netherlands & June $3^{\text {rd }}$ \\
\hline
\end{tabular}




\subsection{Overheating mitigation measures}

Various previous studies have investigated the effect of different overheating reduction measures in vehicles. For example, CFD simulations conducted by Al-Kayiem, Bin M. Sidik, \& Munusammy (2010) indicate that covering the front windshield with an opaque layer can reduce the interior temperature of a parked car up to $8^{\circ} \mathrm{C}$. The same study found that slightly opening the front and rear windows (20mm) can reduce the indoor temperature by $10^{\circ} \mathrm{C}$ and less than $1^{\circ} \mathrm{C}$ respectively. Chakroun \& Al-Fahed (1997) provide experimental results that indicate a $3^{\circ} \mathrm{C}$ reduction in interior temperature when the front windshield is covered and up to $8^{\circ} \mathrm{C}$ when all windows are covered. Additionally, solar powered ventilation can reduce the interior temperature of a parked vehicle up to $10^{\circ} \mathrm{C}$. Solar-reflective glazing and paint can reduce the temperature by $9.5^{\circ} \mathrm{C}$, while the combination of solar-reflective glazing, solar-reflective paint and ventilation can decrease the temperature by $12^{\circ} \mathrm{C}$ (Rugh et al., 2007). Levinson et al. (2011) predict that an increased by about 0.5 solar reflectance $(\rho)$ of the opaque surfaces of the vehicle, can lead to a $5^{\circ} \mathrm{C}-6^{\circ} \mathrm{C}$ reduction in interior temperature. The aforementioned results provide a concise overview of the possible car cabin temperature reductions as a result of different overheating reduction measures and are summarized in Table 4. It is difficult to compare their effectiveness, though, because these results have been obtained for a range of different car types, under dissimilar weather conditions, and using a variety of both experimental and simulation-based methods with little information about specific assumptions. This paper advocates that building performance simulation can be a useful tool for comparing the relative effectiveness of different overheating reduction measures in vehicles.

Table 4: Reduction in cabin air temperature according to each applied measure, as reported in literature

\begin{tabular}{lcc}
\hline \multicolumn{1}{c}{ Measure } & Reduction in cabin air temperature \\
\hline Front windshield covered & $3^{\circ} \mathrm{C}$ (Chakroun \& Al-Fahed, 1997) & $8^{\circ} \mathrm{C}$ (Al-Kayiem et al., 2010) \\
All windows covered & $8^{\circ} \mathrm{C}$ (Chakroun \& Al-Fahed, 1997) & \\
Open front windows & & $10^{\circ} \mathrm{C}$ (Al-Kayiem et al., 2010) \\
Open rear windows & & $<1^{\circ} \mathrm{C}$ (Al-Kayiem et al., 2010) \\
Solar powered ventilation device & $10^{\circ} \mathrm{C}$ (Chakroun \& Al-Fahed, 1997) & \\
Solar-reflective glass and paint & $9.5^{\circ} \mathrm{C}$ (Rugh et al., 2007) & \\
Solar-reflective glass, paint and ventilation & $12^{\circ} \mathrm{C}$ (Rugh et al., 2007) & \\
Increased solar reflectance of opaque surface & & $5^{\circ} \mathrm{C}-6^{\circ} \mathrm{C}$ (Levinson et al., 2011) \\
\hline
\end{tabular}

\subsubsection{Spectrally selective glazing}

Transparent parts in cars are essential for safety, maneuverability and view to outside. However, the accumulation of solar heat gains that reaches the cabin through the windows of parked cars, also plays a dominant role in determining the cooling loads for an automobile air conditioning system (Lahimer et al., 2018) (Sullivan \& Selkowitz, 1988). The implementation of spectrally selective glazing in vehicle windows aims at reducing the amount of solar heat gains that enters the vehicle, without compromising vision. In conventional vehicle windows, a wide spectrum of solar radiation passes through and heats the interior of the vehicle, increasing in that way the air temperature of the cabin. However, only the portion of solar radiation in the visible region of the electromagnetic spectrum is needed to be transmitted through the 
windows, since only that portion can provide visual information to the passengers and most importantly to the driver.

In this study, the performance of an innovative, near-infrared reflecting cholesteric liquid crystal (ChLC) window coating with high visible transmittance, and comparatively low solar transmittance is investigated. Glass properties are taken from (Khandelwal, Loonen, Hensen, Schenning, \& Debije, 2014). For the spectrally selective glazing scenario, the same material (ChLC glazing) was used for all windows. A comparison between regular glass and ChLC windows is presented in Table 5. The glass thickness and conductivity for all windshield and rear-left-right windows were obtained from Fayazbakhsh \& Bahrami (2013).

Table 5: Optical properties of clear and spectrally selective glazing

\begin{tabular}{lccc}
\hline & \multicolumn{2}{c}{ Baseline (clear glass) } & $\begin{array}{c}\text { Spectrally selective } \\
\text { glazing (ChLC) }\end{array}$ \\
\cline { 2 - 3 } Optical properties & Wind shield & $\begin{array}{c}\text { Rear-Left-Right } \\
\text { Window }\end{array}$ & $*$ \\
\hline Solar Transmittance At Normal Incidence & 0.74 & 0.812 & 0.38 \\
Front Side Solar Reflectance At Normal Incidence & 0.07 & 0.075 & 0.52 \\
Back Side Solar Reflectance At Normal Incidence & 0.07 & 0.075 & 0.52 \\
Visible Transmittance At Normal Incidence & 0.868 & 0.885 & 0.8 \\
Front Side Visible Reflectance At Normal Incidence & 0.08 & 0.085 & 0.1 \\
Back Side Visible Reflectance At Normal Incidence & 0.08 & 0.085 & 0.1 \\
Front Side Infrared Hemispherical Emissivity & 0.248 & 0.168 & 0.3 \\
Back Side Infrared Hemispherical Emissivity & 0.248 & 0.168 & 0.3 \\
\hline *For the spectrally selective glazing scenario, the ChLC glazing was used for all windows (Windshield, Rear, &
\end{tabular}

\subsubsection{Solar reflective opaque surfaces}

It has been shown (Hoke \& Greiner, 2005) that a reduced absorptivity in the near infrared (IR) spectrum of the vehicle's opaque surfaces can decrease the vehicle's soak temperatures and reduce air conditioning power consumption. As a result, the vehicle's fuel consumption and the $\mathrm{CO}_{2}$ emissions could also be reduced (Levinson et al., 2011), while still giving customers the flexibility to choose the color of the car to their liking.

For the baseline scenario, as well as every other scenario that does not include the use of high solar reflective opaque surfaces, the properties of black/dark blue-painted surfaces were considered. In that way, the worst case scenario regarding the solar reflectance of the vehicle's opaque surfaces was simulated. For the measure of solar reflective opaque surfaces, a reflectance value of 0.58 was chosen, equivalent to a car body with regular solar-reflective opaque coating. The vehicle surface properties for both occasions were obtained from (Levinson et al., 2011).

\subsubsection{Windshield sunshades}

The third measure that is investigated in this study is the covering of the windshield with movable sunshades. Two separate occasions are examined: exterior and interior shading. The use of windshield sunshades aims at reducing the sunlight from entering the vehicle and is a common technique, especially in regions with high temperatures(Jasni \& Nasir, 2012) (Aljubury, Farhan, \& Mussa, 2015).It shares similarities with the concept of adaptive building facades, a high-potential way of reducing building energy consumption while improving occupants' comfort (Loonen, R. C. G. M., Trčka, M., Cóstola, D., Hensen, J. 
L. M., 2013). The properties of the shadings that were used in the simulation correspond to typical values for exterior and interior window shades in buildings (i.e. 0.4 solar transmittance and 0.5 solar reflectance).

\section{Analysis of predicted effect of overheating mitigation measures}

\subsection{Relative comparison}

For each climate and vehicle type, six different scenarios were considered: i) baseline, ii) solar reflective opaque surfaces, iii) spectrally selective glazing (ChLC glazing), iv) interior windshield shading, v) exterior windshield shading, vi) combination of solar reflective opaque surfaces and spectrally selective glazing. That means that 24 simulations were conducted for each vehicle.

Figure 8 shows the cabin temperature for the two baseline scenarios over the course of one day. The simulation results for the spectrally selective glazing scenarios are also shown, to highlight the reduction of the interior air temperature, and how it changes during the day.

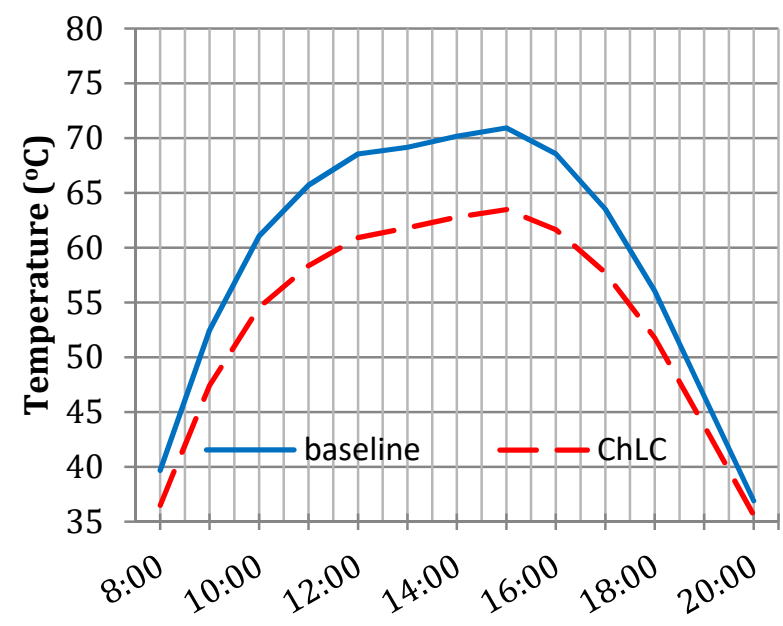

Time (h)

(a)

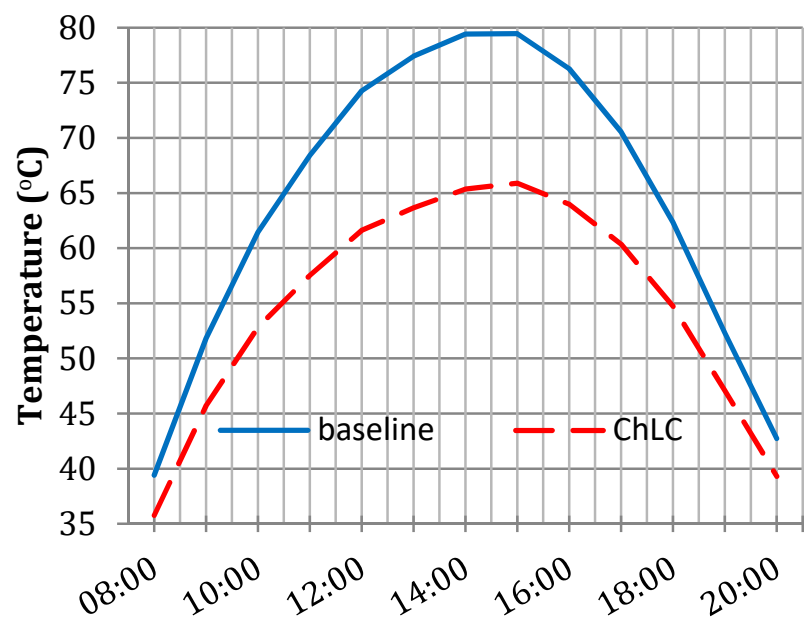

Time (h)

(b)

Fig.8. Spectrally selective glazing comparison, for High-Temperature/High-Radiation (case D - Thessaloniki-July). Citroën C3 (a) and Tesla S (b). ChLC (red) refers to ChLC glazing spectrally selective glazing (scenario iii).

A similar daily pattern was observed when different weather conditions were taken into consideration. Fig. 9 summarizes these results. As expected, the effect of spectrally selective glazing on the cabin's air temperature is more noticeable in climates with higher radiation intensity. Also, the average differences of air temperature from baseline, for the examined climatic conditions, are significantly higher in Tesla S. This can be explained by the fact that Tesla $\mathrm{S}$ has a panoramic glass roof, thus making the effect of glazing on the inside air temperature, more significant.

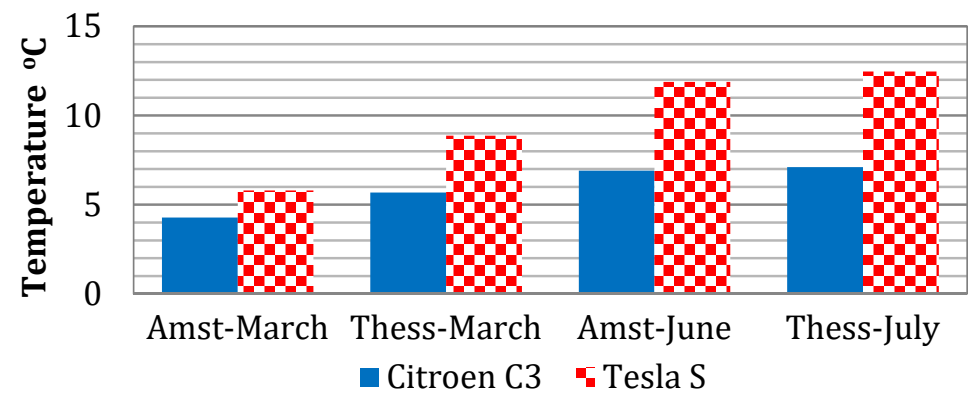


Fig.9: Average difference in cabin air temperature (11:00-17:00) from baseline scenario when spectrally selective glazing is used (scenario iii). "Amst-March" refers to March 6", Amsterdam (Low Temperature, Low Radiation), "Thess-March" to March 15th, Thessaloniki (Medium Temperature, Medium-Low Radiation), "Amst-June" to June $3^{\text {rd }}$, Amsterdam (Medium Temperature, Medium-High Radiation) and "Thess-July" to July $4^{\text {th }}$, Thessaloniki (High

Temperature, High Radiation).

For the measure of solar reflective opaque surfaces, where the black/dark blue-colored opaque surfaces were replaced by solar-reflective surfaces, a significant reduction of interior air temperature was observed for all cases. In particular, the reduction of interior air temperature was more pronounced in climatic conditions with higher temperatures and higher values of solar radiation. Fig. 10 illustrates the maximum interior air temperature for both vehicles and all the climatic conditions that were examined. In case D (High Temperature-High Radiation, Thessaloniki-July $4^{\text {th }}$ ) the use of solar reflective opaque surfaces results in maximum interior air temperatures that are $10.7^{\circ} \mathrm{C}$ and $13.3^{\circ} \mathrm{C}$ lower than in the baseline scenario, in the case of Citroën C3 and Tesla $\mathrm{S}$ respectively.

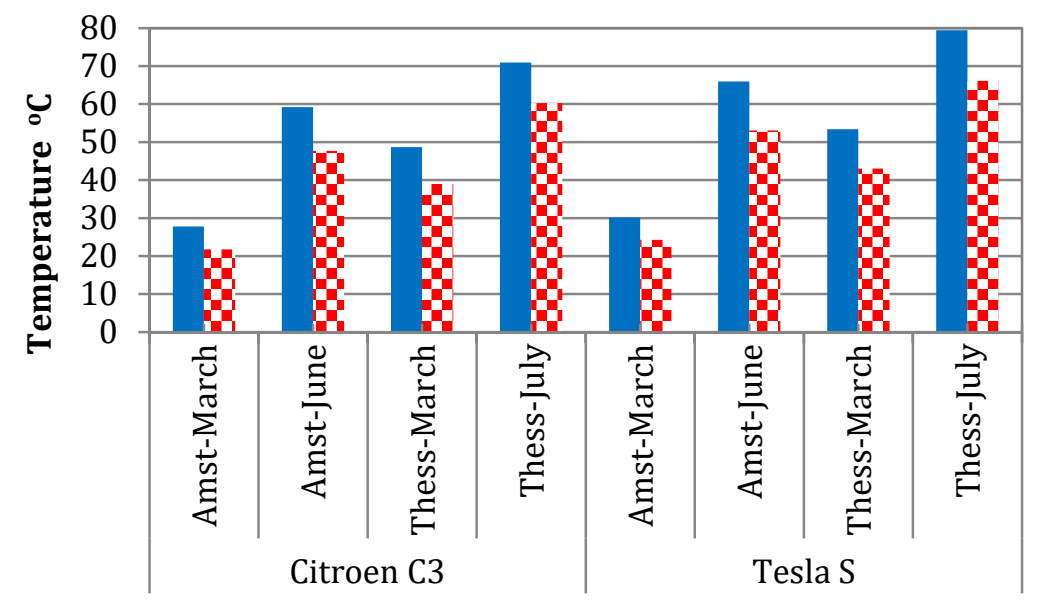

Fig.10: Maximum interior air temperature for baseline (blue) and solar reflective opaque surfaces (checkered red), for both vehicles. "Amst-March" refers to March 6" ${ }^{\text {th }}$, Amsterdam (Low Temperature, Low Radiation), "Thess-March" to March 15 $5^{\text {th }}$, Thessaloniki (Medium Temperature, Medium-Low Radiation), "Amst-June" to June $3^{\text {rd }}$, Amsterdam (Medium Temperature, Medium-High Radiation) and "Thess-July" to July $4^{\text {th }}$, Thessaloniki (High Temperature, High Radiation).

Regarding the use of interior and exterior window shading, Fig.11 shows that exterior shading leads to a higher reduction of the inside air temperature compared to interior shading, for all the climatic conditions and both vehicles. However the difference in temperature reduction between interior and exterior shading is not very large. As in the case with spectrally selective glazing, both interior and exterior shading leads to a greater reduction of the air temperature when Tesla $S$ is taken under examination, due to its larger glass window area. Contrariwise, although that in the case of spectrally selective glazing, temperature reduction is increasing with higher exterior temperatures and solar radiation, in the case of interior and exterior shading, the maximum value of temperature reduction occurs in climate $\mathrm{B}$ (medium temperature, medium-low radiation)when Citroën C3 is examined. This can be explained by the fact that since the vehicle is parked with south orientation and only the windshield is covered with sunshades, the sunshades block a bigger part of the solar radiation; whereas in cases $C$ and $D$ the interior temperature is 
influenced in a lesser degree by the radiation that passes through the windshield. In the case of Tesla $S$, the temperature difference from baseline is almost the same for climatic conditions $B, C$ and $D$.

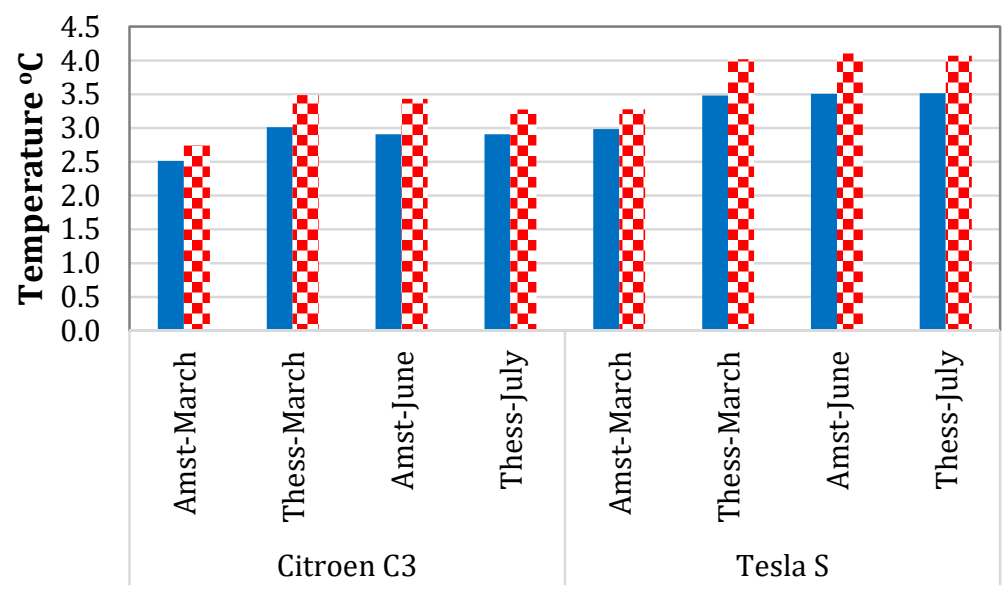

- Interior shading ' 'u' Exterior shading

Fig.11: Maximum difference from baseline for interior shading (blue) and exterior shading (checkered red) for both vehicles. "Amst-March" refers to March 6 ${ }^{\text {th }}$, Amsterdam (Low Temperature, Low Radiation), "Thess-March" to March 15th , Thessaloniki (Medium Temperature, Medium-Low Radiation), "Amst-June" to June $3^{\text {rd }}$, Amsterdam (Medium Temperature, Medium-High Radiation) and "Thess-July" to July $4^{\text {th }}$, Thessaloniki (High Temperature, High Radiation).

Fig. 12 quantifies the temperature reduction potential of the different overheating mitigation measures for four climatic conditions and both vehicles. For Citroën C3, we observe the same trend for all the overheating mitigation measures for all the climatic conditions: the most effective mitigation measure is shown to be the combination of Cholesteric Liquid Crystal (ChLC) glazing and solar-reflective surfaces, followed by the reflective surfaces only, ChLC glazing and exterior shading. The same pattern can be observed for Tesla S, except for the fact that the lines corresponding to ChLC glazing and solar-reflective surfaces, almost match each other, especially during midday hours where in fact, ChLC glazing leads to slightly lower temperatures compared to reflective opaque surfaces. 


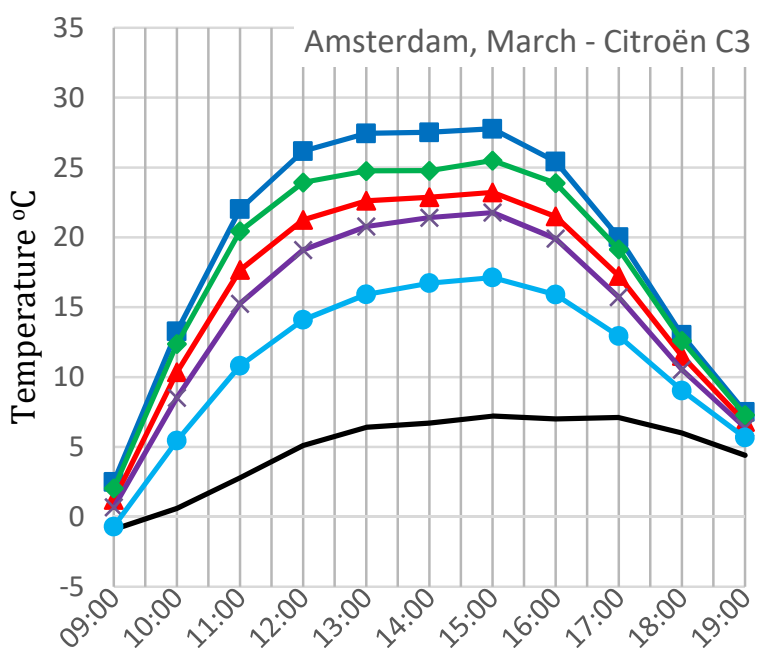

Fig. $12 a$
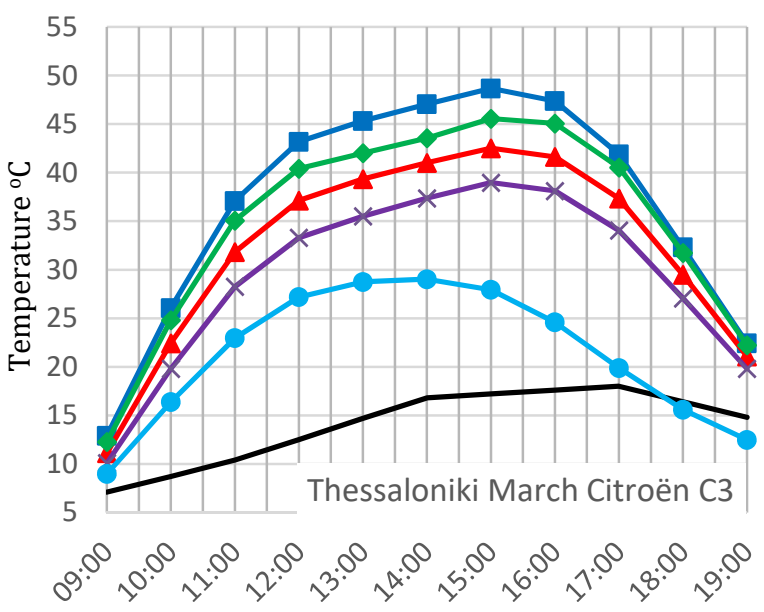

Fig. $12 c$

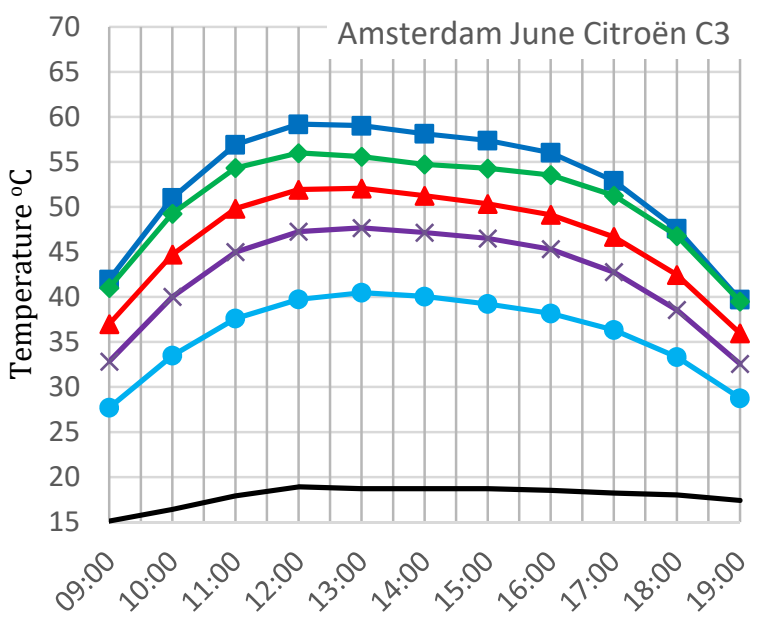

Fig. $12 e$

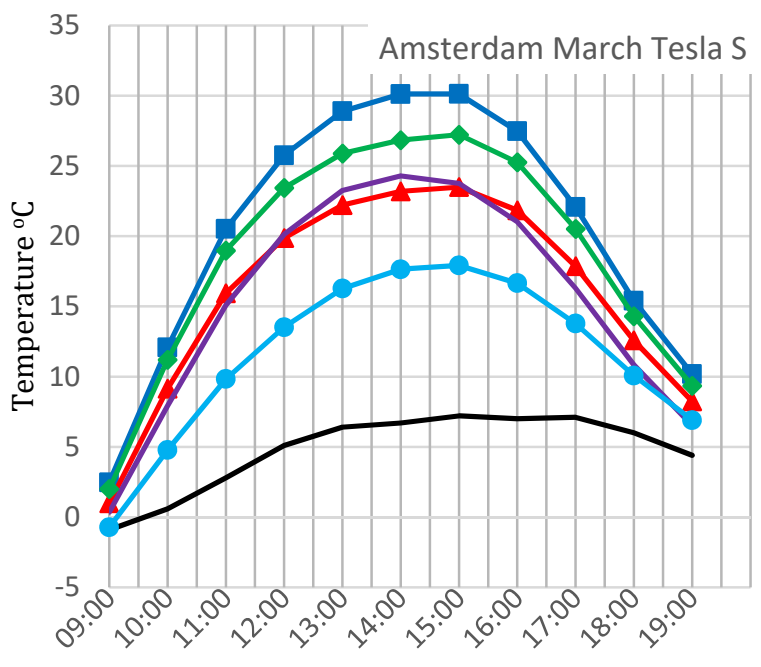

Fig. $12 b$

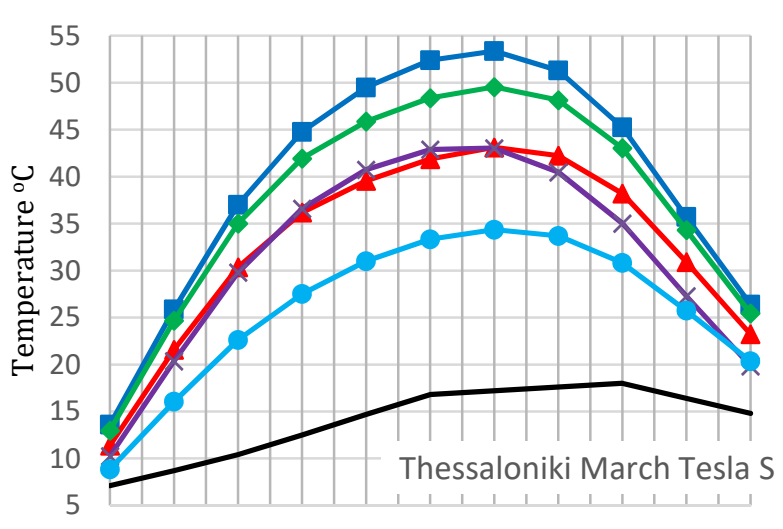

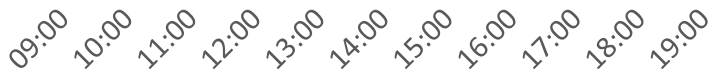

Fig. $12 d$

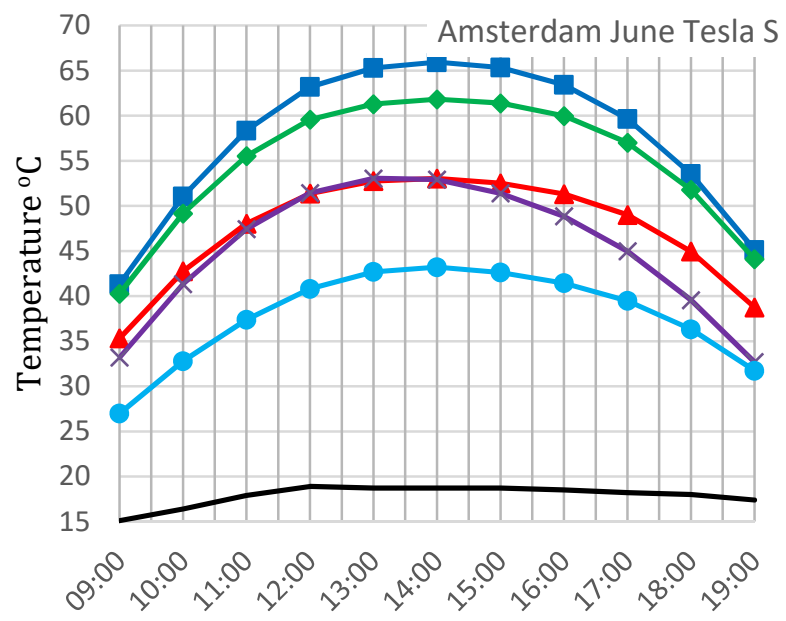

Fig. $12 f$ 


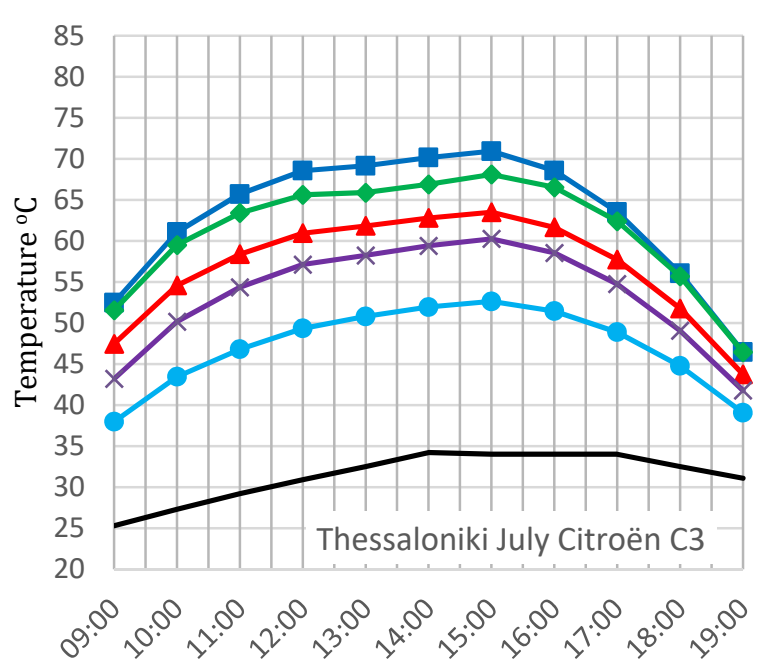

Fig. $12 g$

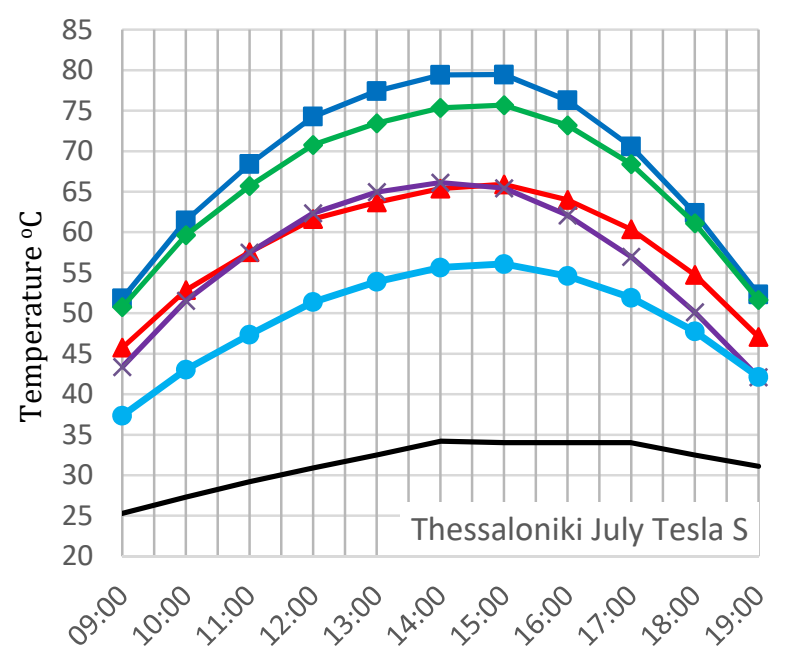

Fig. $12 h$

Fig.12: Hourly cabin air temperature for each overheating mitigation compared to baseline cabin air temperature and ambient temperature. Baseline $\mathbf{-}$, exterior shading $\diamond, \operatorname{ChLC}$ glazing $\mathbf{\Delta}$, solar-reflective opaque coating $\times$, combination of ChLC glazing and solar-reflective opaque coating $\bullet$, ambient temperature - .

\subsection{Annual comparison}

Regarding the behavior of the different overheating mitigation measures over the course of a whole year, Fig. 13 provides the temperature duration curves for all scenarios, climatic conditions and vehicles. These curves represent the mean cabin air temperature between $8 \mathrm{am}$ and $6 \mathrm{pm}$ for each day. The chosen visualization method helps in building understanding that all measures cause a reduction of the daily mean cabin air temperature, and that this effect is strongest during the warmest period of the year. In Amsterdam, there is a clear peak, with roughly 50 days with a mean cabin temperature higher than $42^{\circ} \mathrm{C}$ (baseline). The simulation results show that increased reflectance of transparent and opaque parts can obtain a significant indoor temperature reduction during this period. From these results, it can be induced that the overheating reduction potential can mostly be attributed to lower transmission of shortwave radiation. Because ambient temperature appears to have a lower impact on the results, it is assumed that a similar mitigation potential can be achieved in colder climates with irradiance conditions comparable to Amsterdam (e.g. Nordic climates).

The temperature duration curve in Thessaloniki shows a quite different, much more linear shape. The difference in peak temperatures between the two cities is not so large, but Thessaloniki shows much higher temperatures from the $10^{\text {th }}$ to $250^{\text {th }}$ warmest day. It is interesting to observe that the indoor temperature that gets exceeded for more than 150 days per year $\left(45^{\circ} \mathrm{C}\right.$ for Citroën $\mathrm{C} 3$ and $47{ }^{\circ} \mathrm{C}$ for Tesla S) in the baseline scenario is never reached in the design variant that combines reflective glazing and opaque surfaces. The temperature distribution curves also illustrate that the measures for windows and opaque elements work complementary. Their combined application has nearly double the effect of the individual measure, for all cases considered. 

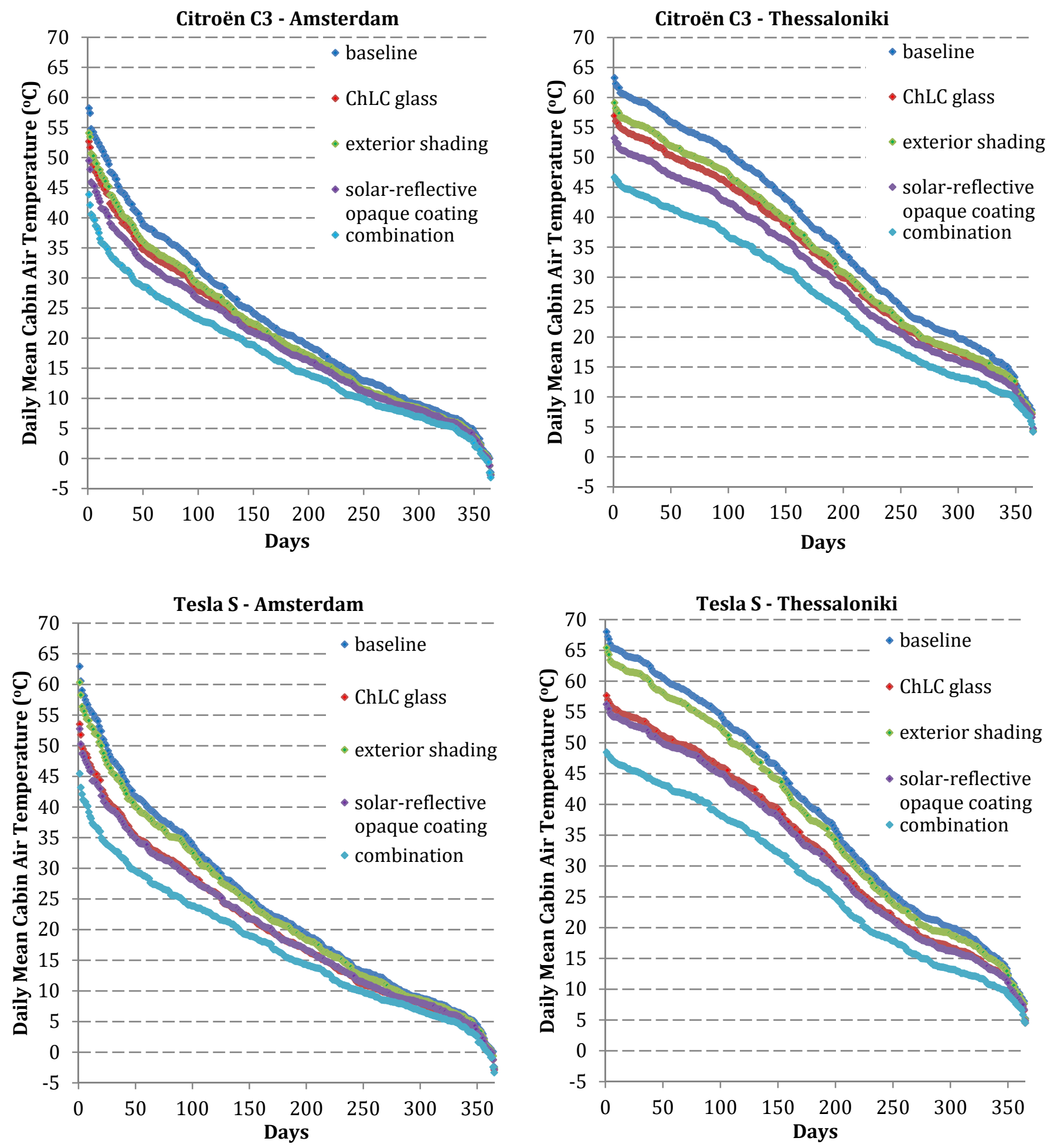

Fig.13: Annual temperature duration curves for all scenarios, climatic conditions and vehicles. Baseline (blue), exterior shading (green), ChLC glazing (red), solar-reflective opaque coating (purple), combination of ChLC glazing and solar-reflective opaque coating (light blue).

\section{Concluding remarks}


Overheating of a parked vehicle's cabin can cause thermal discomfort of the driver and its passengers. Due to the widespread use of automobile air conditioning (AAC) systems, this also has a direct impact on the fuel consumption of the vehicle or, in the case of an electric vehicle, its cruising range. Given the fact that the automotive sector needs to become more sustainable, there is a pertinent need for developing solutions that can simultaneously address both the comfort issues and the environmental concerns. This could be done by reconsidering the design of the vehicles' shell. In this paper, we have demonstrated that tools and techniques from the building sector can play an enabling role in this process.

By comparing the simulation output with measurement results from a thermal soak test, it was demonstrated that EnergyPlus, a widely used BPS tool, is also capable of producing accurate estimations of the heat transfer in parked vehicles. There was a high level of agreement between the measured and predicted warm-up and cool-down rates $\left({ }^{\circ} \mathrm{C} / \mathrm{h}\right)$, and also the peak soak temperature was predicted with reasonable accuracy. It should be noted, though, that the tuning of the internal mass factor that accounts for thermal capacitance is an important parameter to get right, because this can have a large influence on the end result. Unfortunately, there is currently very little guidance about how this tuning could be done in an adequate way. Further research for developing better models could additionally also focus on finding ways to take the thermal stratification into account, that occurs as a result of non-uniform absorptance of short-wave radiation, and the different air-flow patterns inside the cabin. This becomes especially relevant when one is interested in not only predicting global thermal comfort conditions, but also would like to investigate local discomfort indices.

With the use of the validated simulation model, three overheating mitigation measures were investigated: i) use of spectrally selective glazing for the vehicle windows, ii) solar reflective opaque surfaces and iii) the placing of shadings on the windshield of the vehicle. The geometries of two vehicles were selected: (a) Citroën C3, a typical B-segment car, and (b) Tesla model S, an electric luxury sedan with panoramic sunroof. The simulations were conducted for two locations (Amsterdam and Thessaloniki) and compared on characteristic days, as well as annual performance evaluations.

A window with cholesteric liquid crystal ( $\mathrm{ChLC}$ ) near-infrared reflecting coating can cause an average difference of temperature as high as $12.5^{\circ} \mathrm{C}$ compared to the baseline scenario. The comparison between interior and exterior shading led to the conclusion that the latter leads to a slightly higher reduction of the inside air temperature compared to interior shading, for all the climatic conditions and both vehicles. Significantly reducing the solar and thermal absorptance of the vehicle's opaque surfaces, as in the case of a conventional car with solar-reflective opaque coating, is a passive method that can cause a significant reduction of interior air temperature in climatic conditions with high temperatures and high levels of solar radiation. The combination of a solar-reflective opaque coating and ChLC glazing could reduce significantly the cabin air temperature during the thermal soak test with an average temperature reduction ranging from $10.4^{\circ} \mathrm{C}$ to $22.1^{\circ} \mathrm{C}$. This difference in inside air temperatures can positively affect the thermal comfort of the passengers, as well as the energy consumption of the vehicle, and is particularly important for warm climates, that experience high levels of solar radiation and temperatures throughout the year. The investigated overheating mitigation methods can be implemented in the existing car designs with little need for extra materials and components. Follow-up studies should be carried out to enable detailed comparisons of costs and benefits, accounting for aspects such as: materials use, weight increase, fuel reductions and/or extended driving range, and qualitative or quantitative indications of the monetary value of increased passengers' comfort. 
Future research could continue the use of BPS for investigating the performance of these and other overheating mitigation strategies in different climates. The BPS software can also be used to predict the thermal performance of other vehicle types, such as campervans or mass transit cabins. In addition, it would be interesting to use the capabilities of the BPS models to predict passenger comfort as a function of local surface temperatures and airflow patterns. These studies could be extended from the thermal to the daylight domain, to also evaluate the consequences of the proposed solutions in terms of glare disturbance or color perception.

Although it might require significant changes to the current modeling paradigms in BPS tools, it will be a logical next step to also assess the performance of moving vehicles. Modeling and validation challenges to be overcome include treatment of convective heat transfer as a function of driving speed, dynamic shading from neighboring obstructions and changes in incident solar radiation due to changes in driving direction. Once this has been accomplished, it becomes possible to take advantage of additional features of BPS software. For instance, using heating, ventilation and air-conditioning (HVAC) modeling libraries to propose innovative AAC system designs, and optimization of set-points and air diffuser settings to improve passengers' comfort. Such studies can then be used to make informed decisions about the impact of AAC energy use in relation to the driving range of electric vehicles.

\section{Acknowledgments}

The necessary equipment for executing the experimental study and the meteorological data for the validation were provided by Titan Cement Co S.A. Special thanks to Dr. Stelios Antiohos for his guidance in the experimental study.

\section{References}

Abd-Fadeel, W., \& Hassanein, S. (2013). Temperature Variations in a Parked Car Exposed To Direct Sun During Hot and Dry Climates. International Journal of Automobile Engineering, 3(1), 75-80.

Aljubury, I. M., Farhan, A., \& Mussa, M. A. (2015). Experimental Study of Interior Temperature Distribution Inside Parked Autonobile Cabin.Journal of Engineering, 21(3).

Al-Kayiem, H. H., Bin M. Sidik, M. F., \& Munusammy, Y. R. (2010). Study on the Thermal Accumulation and Distribution Inside Parked Car Cabin. American Journal of Applied Sciences , 7(6), 784-789.

Amaral, A. R., et al. (2016). A thermal performance parametric study of window type, orientation, size and shadowing effect. Sustainable Cities and Society, 26, 456-465.

Carley, S., Krause, R. M., Lane, B. W., \& Graham, J. D. (2016). Intent to purchase a plug-in electric vehicle : A survey of early impressions in large US cites. Transportation Research Part D, 18(2013), 3945.

Chakroun, W., \& Al-Fahed, S. (1997). Thermal comfort analysis inside a car. International Journal of Energy Research, 21(4), 327-340.

Crawley, D. B., Hand, J. W., Kummert, M., \& Griffith, B. T. (2008). Contrasting the capabilities of building 
energy performance simulation programs, Building and Environment, 43, 661-673.

Dadour, I. R., Almanjahie, I., Fowkes, N. D., Keady, G., \& Vijayan, K. (2011). Temperature variations in a parked vehicle. Forensic Science International, 207(1-3), 205-211.

Daly S. (2011). Automotive air-conditioning and climate control systems. Butterworth- Heinemann, Lincare House, Jordan Hill, Oxford OX2 8DP, 30 Corporate Drive, Suite

Devonshire, J. M., Sayer, J. R. (2005). Radiant Heat and Thermal Comfort in Vehicles, Human Factors, 47(4), 827-839.

Fayazbakhsh, M. A., \& Bahrami, M. (2013). Comprehensive modeling of vehicle air conditioning loads using heat balance method. SAE International .

Fiori, C., Ahn, K., \& Rakha, H. A. (2016). Power-based electric vehicle energy consumption model: Model development and validation. Applied Energy, 168, 257-268.

Fiser, J., Pokorny, J., Podola, D., \& Jicha, M. (2013). Experimental investigation of car cabin environment during real traffic conditions. Engineering MECHANICS, 20(3), pp. 229-236.

Grundstein, A., Meentemeyer, V., \& Dowd, J. (2009). Maximium vehicle cabin temperatures under different meteorological conditions. International Journal of biometerology , 255-261.

Han, T., \& Chen, K.-H. (2009). Assesment of various environmetnal thermal loads on passenger compartment soak and cool-down analyses. SAE Technical Papers, (April), 1-11.

Hoke, P., \& Greiner, C. (2005). Vehicle Paint Radiation Properties and Affect on Vehicle Soak Temperature, Climate Control System Load, and Fuel Economy. SAE Technical Paper (2005-01-1880).

Jasni, M. A., \& Nasir, F. M. (2012). Experimental Comparison Study of the Passive Methods in Reducing Car Cabin Interior Temperature. International Conference on Mechanical, Automobile and Robotics Engineering, (pp. 229-233). Penang, Malaysia.

Kambly, K., \& Thomas, B. H. (2015). Geographical and temporal differences in electric vehicle range due to cabin conditionning energy consumption. Journal of Power sources , 468-475.

Khandelwal, H., Loonen, R. C. G. M., Hensen, J. L. M., Schenning, A. P., \& Debije, M. G. (2014). Application of broadband infrared reflector based on cholesteric liquid crystal polymer bilayer film to windows and its impact on reducing the energy consumption in buildings. Journal of Materials Chemistry ,A, 2, 14622-14627.

Khayyam, H., Kouzani, A. Z., Hu, E. J., \& Nahavandi, S. (2011). Coordinated energy management of vehicle air conditioning system. Applied Thermal Engineering, 31(5), 750-764.

Konstantinov, M., \& Wagner, C. (2016). Numerical Simulation of the Thermal Comfort in a Model of a Passenger Car Cabin.In Dillmann A., Heller G., Krämer E., Wagner C., Breitsamter C. (eds) New Results in Numerical and Experimental Fluid Mechanics X. Notes on Numerical Fluid Mechanics and Multidisciplinary Design, vol. 132, 283-393. 
Lahimer, A. A., Alghoul, M. A., Sopian, K., \& Khrit, N. G. (2018). Potential of solar reflective cover on regulating the car cabin conditions and fuel consumption. Applied thermal engineering, 143, 59-71.

Lenzuni, P. et al. (2014). Is driving in a hot vehicle safe? . International Journal of Hypothermia, 6736(May), 250-257.

Levinson, R., Pan, H., Ban-weiss, G., Rosado, P., Paolini, R., \& Akbari, H. (2011). Potential benefits of solar reflective car shells : Cooler cabins, fuel savings and emission reductions. Applied Energy, 88(12), 43434357.

Lin, Tzu-Ping et al. (2010). Passenger thermal perceptions, thermal confort requirements and adaptations in short and long-haul vehicles. International journal of biogiometry,3, 221-230.

Liu, K., Wang, J., Yamamoto, T., \& Morikawa, T. (2017). Exploring the interactive effects of ambient temperature and vehicle auxiliary loads on electric vehicle energy consumption. Applied Energy.

Loonen, R. C. G. M., Trčka, M., Cóstola, D., Hensen, J. L. M. (2013). Climate adaptive building shells : State-of-the-art and future challenges, Renewable and Sustainable Energy Reviews,25, 483-493.

Lustbader, J. A., Rugh, J. P., Rister, B. R.\& Venson, T. S. (2011). CoolCalc : A Long-Haul Truck Thermal Load Estimation Tool. SAE World Congress 2011.

Minjares, R. (2011). Refrigerants for light-duty passenger vehicle air conditionning systems. The international coincil on clean transportation 2011,3.

Nielsen, F., Uddheim, Å., \& Dalenbäck, J. (2016). Potential energy consumption reduction of automotive climate control systems. Applied Thermal Engineering, 106, 381-389.

Pan, H., Qi, L., Zhang, X., Zhang, Z., Salman, W., Yuan, Y., \& Wang, C. (2017). A portable renewable solar energy-powered cooling system based on wireless power transfer for a vehicle cabin. Applied energy, 195, 334-343.

Rugh, J. (2002). Integrated Numerical Modeling Process for Evaluating Automobile Climate Control Systems. Proceedings of Future Car Congress, Arlington, VA, (724), 70-78.

Rugh, J. P., Chaney, L., Lustbader, J., \& Meyer, J. (2007). Reduction in vehicle temperatures and fuel use from cabin ventilation, solar-reflective paint, and a new solar-reflective glazing (No. 2007-01-1194). SAE Technical Paper.

Sadineni, S. B., Madala, S., \& Boehm, R. F. (2011). Passive building energy savings : A review of building envelope components. Renewable and Sustainable Energy Reviews, 15(8), 3617-3631.

Sullivan, R., \& Selkowitz, S. (1988). Effects of glazing and ventilation options on automobile air conditioner size and performance. Applied Science Division Lawrence Berkeley Laboratory.

U.S. Department of Energy. (2016, March 31). Engineering Reference. EnergyPlus Version 8.5 Documentation.

Weilenmann, M. F., Vasic, A., Stettler, P., \& Novak, P. (2005). Influence of Mobile Air-Conditioning on Vehicle Emissions and Fuel Consumption : A Model Approach for Modern Gasoline Cars Used in Europe, 9601-9610. 
Wyon, David, \& Norin, F. (1996). Effects of moderate heat stress on driver vigilance in a moving vehicle. Ergonomics , 61-75.

Zhang, Z., Liu, C., Chen, X., Zhang, C., \& Chen, J. (2017). Annual energy consumption of electric vehicle air conditioning in China. Applied Thermal Engineering, 125, 567-574. 